\title{
Metodologia para seleção de políticas públicas de incentivo ao uso da bicicleta como modelo de transporte
}

\author{
Methodology for selecting public policies to promote the use of bicycles as a \\ transport model
}

Guilherme Moyses Pfeffer ${ }^{1 *}$, Walber Paschoal da Silva ${ }^{1}$

\section{RESUMO}

O objetivo deste trabalho foi desenvolver uma metodologia de apoio aos planejadores urbanos e de transportes, para a definição de políticas públicas capazes de fomentar o uso da bicicleta em suas cidades. Os parâmetros utilizados abordaram questões como, análise das cidades mais amigáveis aos ciclistas, estudo da percepção da população e de especialistas sobre o assunto, além do estudo de fatores geográficos intervenientes. Dados sobre o planejamento cicloviário de regiões amigáveis aos ciclistas orientaram a criação de uma lista de políticas públicas de referência. Uma pesquisa de campo permitiu conhecer a percepção da população sobre o uso da bicicleta, indicando as demandas mais urgentes para incentivar o uso da bicicleta na cidade, e a percepção de especialistas sobre as políticas públicas mais indicadas para esse fim. As hipóteses levantadas foram testadas por meio de um estudo de caso, realizado na cidade de Niterói-RJ, e os resultados revelaram uma grande incidência de três estratégias: construção, melhoria e manutenção de ciclovias e ciclofaixas, $100 \%$; criação e melhoria de estacionamentos para bicicletas, $95,7 \%$; campanhas para o estímulo ao uso da bicicleta e ao bom comportamento no trânsito, 82,6\%.

Palavras-chave: Bicicleta; Planejamento cicloviário; Políticas públicas de transportes; Planejamento urbano.

\section{ABSTRACT}

The objective of this paper was to develop a methodology to support urban and transport planners during the definition of public policies capable of promoting the use of bicycles in their cities. The parameters used address issues such as analysis of the friendlier cities for cyclists, study of the perception of the population and experts on the subject, in addition to the study of intervening geographic factors. Data surveys were carried out on cycle planning in cyclist-friendly regions, in order to create a list of reference public policies. A field survey was also carried out to understand the population's perception of the use of bicycles, and to understand the most urgent demands to encourage the use of bicycles in the city, as well as a survey on the perception of specialists about the most suitable public policies for that end. Through a case study, carried out in the city of Niterói-RJ, the hypotheses elaborated in this work were tested, and the results revealed a great incidence of three strategies: construction, improvement and maintenance of cycle paths and cycle lanes, $100 \%$; creation and improvement of bicycle parking, $95.7 \%$; campaigns to encourage the use of bicycles and good behavior in traffic, $82.6 \%$.

Keywords: Bicycle; Cycle planning; Public transport policies; Urban planning.

\footnotetext{
${ }^{1}$ Universidade Federal Fluminense. *E-mail: walberpaschoal@id.uff.br
} 


\section{INTRODUÇÃO}

A utilização de veículos movidos a combustíveis fósseis é extremamente danosa à saúde da população e ao planeta. Segundo o censo do Instituto Brasileiro de Geografia e Estatística (IBGE), no ano de 2017 o Brasil contava com uma frota de cerca de 51,3 milhões de carros de passeio (IBGE, 2017). O crescimento acelerado das cidades, muitas vezes, desordenado, associado à falta de um planejamento efetivo do sistema de transportes, capaz de promover o uso do transporte público e dos modos de transporte não motorizados, entre os quais se destaca a bicicleta, acaba por incentivar a construção de grandes rodovias e o uso do transporte motorizado (UN-HABITAT, 2013).

O destaque para a bicicleta ocorre devido às várias vantagens oferecidas, pois, comparada aos modos de transportes motorizados, não emite $\mathrm{CO}_{2}$, é benéfica para a saúde de seus usuários, além de ser acessível a todas as classes sociais. O custo médio de aquisição, e de manutenção, de uma bicicleta é significativamente inferior aos dos modos motorizados, possibilitando às camadas mais pobres da sociedade, um meio de transporte viável. Mais um ponto de destaque, que transforma a bicicleta em um atrativo para todas as classes sociais é o reduzido custo por km percorrido, que, segundo estudo realizado nas cidades do Rio de Janeiro e Porto Alegre, é de 0,101 (R \$/km), contra 0,324 do ônibus, 0,481 da moto, 0,723 do carro a álcool, e 0,763 do carro a gasolina (ROSENBERG ASSOCIADOS, 2015).

No deslocamento porta-a-porta, nas grandes áreas urbanas, a bicicleta é mais ágil do que os carros e os ônibus, em distâncias de até $5 \mathrm{~km}$, e tem com um custo total onze vezes menor do que um carro popular, se analisada a mesma distância para um só usuário (BRASIL, 2007). A bicicleta é considerada um transporte que não coloca em risco ecossistemas e a saúde pública. Se for analisado o custo-benefício, a bicicleta possui uma balança favorável em termos de produção de carbono, pois esta gera somente consumo de $\mathrm{CO}_{2}$ durante a sua fabricação, passando o resto de sua vida útil sendo utilizada sem emissão do mesmo.

A iniciativa do poder público para incentivar o uso da bicicleta é determinante para o sucesso da mesma, de forma a influenciar essa escolha pela bicicleta. Algumas formas de estímulo financeiro, também aumentam de forma considerável a opção por esse modal de transporte (FRANCO, 2011, apud GENGHINI, 2014). Os investimentos em políticas de estímulo ao uso da bicicleta, e em infraestrutura de qualidade, geram grandes 
benefícios para a cidade. Segundo um estudo feito em Helsinki, capital de Finlândia, a cada 1 euro investido na construção de novas ciclovias existe um retorno de 7,80 euros em benefícios (CITY OF HELSINKI, 2015).

No quesito saúde, os benefícios também são amplos, pois usuários de transportes não motorizados tendem a ser mais saudáveis e ter menos doenças cardiovasculares do que os que utilizam transporte motorizado (ibid). Os benefícios, principalmente relacionados a doenças do coração, podem gerar um aumento de $10 \%$ a $25 \%$ no tempo de vida (UN-HABITAT, 2013). Segundo estudos na Cidade de Groningen, ciclistas geralmente ficam 7,4 dias do ano doentes, contra 8,7 dos não ciclistas (CITY OF GRONINGEN, 2015).

No Brasil, a expansão do sistema cicloviário ainda apresenta mais uma vantagem, pois atualmente o país é o quarto maior produtor de bicicletas do mundo, e possui a quinta maior frota mundial (BRASIL, 2007). Esse fato também favorece à expansão do mercado nacional e até a influenciar países próximos, principalmente os do Mercado Comum da América do Sul (MERCOSUL), a aumentarem suas frotas, tendo em vista a facilidade de importação e exportação.

Nesse cenário, este trabalho tem como objetivo criar uma metodologia capaz de auxiliar aqueles responsáveis pelo planejamento urbano e de transportes, durante a definição das políticas públicas de incentivo ao uso da bicicleta, mais adequadas às características de cada cidade. Políticas públicas bem planejadas são capazes de melhorar o desempenho do sistema de transportes da cidade, reduzindo o volume de tráfego de veículos automotores nas vias principais, por meio do incremento do número de usuários de bicicleta.

\section{REFERENCIAL TEÓRICO}

A origem da palavra bicicleta vem do francês bicyclette. Contudo, sua etimologia original vem de kýklos e cyclus, respectivamente, do Grego e do Latim. O prefixo bi, de origem latina, indica a existência de duas rodas. No Código de Trânsito Brasileiro (CTB, 1997) a bicicleta é definida como "veículo de propulsão humana, dotado de duas rodas, não sendo, para efeito deste Código, similar à motocicleta, motoneta e ciclomotor".

$\mathrm{Na}$ Europa, o estimulo a utilização da bicicleta vem dentro da pauta da Comunidade Europeia, a fim de reduzir a emissão de gases poluentes (ROSENBERG 
ASSOCIADOS, 2015). Verifica-se, então, que investimentos em políticas públicas são fundamentais para aumentar as taxas de uso da bicicleta e a eficiência em seu uso. Países onde ocorrem investimentos em infraestrutura cicloviária de extrema qualidade, possibilitam que os usuários alcancem velocidades médias de $19 \mathrm{~km} / \mathrm{h}$, podendo assim superar em torno de 3 a 4 vezes o tempo de deslocamento a pé (ibid).

Programas para melhorar a integração da bicicleta com os demais modais como, por exemplo, na Alemanha entre 1975 e 1998, geraram melhoras significativas. Nesse período foi notada uma redução em $66 \%$ dos acidentes fatais e um aumento de cerca de $30 \%$ no aumento de ciclistas (PREFEITURA DA CIDADE DE SÃO PAULO, 2006). O crescimento do modal cicloviário na Alemanha vem desde meados da década de 70 , quando as cidades alemãs aprovaram políticas públicas que garantissem ao ciclista chegar ao destino de forma mais rápida, mais segura e com maior conveniência (PUCHER, 1997).

Atualmente, têm-se como a maior referência mundial de ciclismo a Holanda, com foco em Amsterdã. Casos como o da cidade universitária de Groningen, onde somente dentro da estação de trem existe estacionamento para 10.000 bicicletas, é uma realidade de infraestrutura presente por todo o país (BBC, 2013). Porém, a história holandesa tem início não muito feliz na década de 1950 e 1970, onde as bicicletas quase foram expulsas devido ao crescente número de carros, caindo de cerca $80 \%$ de todas as viagens feitas, para cerca de apenas 20\% (VAN DER ZEE, 2015). Atualmente Amsterdã possui taxas de uso da bicicleta próximas a $40 \%$ e em ascendência.

A Dinamarca merece destaque pelo seu crescimento acelerado e sua atual posição dominante no quesito de sistemas cicloviários, com cerca de $12.000 \mathrm{~km}$ de malha cicloviária espalhada pelo país. Na cidade de Copenhague, por exemplo, 55\% da população usa a bicicleta diariamente com a finalidade de ir e vir do trabalho, gerando cerca de 1.17 milhões de $\mathrm{km}$ rodados de bicicleta por dia, e, mesmo no inverno, $70 \%$ dos usuários continuam a atividade apesar da neve (DANIS ARCHITECTURE CENTER, 2014). As políticas dinamarquesas conseguiram fundir o uso da bicicleta à cultura de sua população. Os serviços postais da cidade contam com mais de 300 bicicletas destinadas a este fim e grande parte das empresas possuem infraestrutura necessária para os funcionários poderem trocar de roupa e/ou tomarem banho após o percurso percorrido (BERGER, 2014). 
O crescimento dos usuários de bicicleta vem crescendo consideravelmente nos EUA e Canadá. Segundo estudos, entre os anos de 1977 e 2009, o número de ciclistas triplicou. Outro dado que pode demostrar isso é o fato de que em 2012 foram registrados 865.000 cidadãos utilizando a bicicleta como meio de transporte para alcançar seu destino, um crescimento de $11 \%$ em relação a 2009 (RELIANCE FOUNDRY, 2015).

O sistema de aluguel de bicicleta, mais comumente conhecido como bicyclesharing systems, é uma forma de incentivar ao público uma maior oportunidade de trocar e repensar seus modos de transitar pela cidade. Ao redor de todo o mundo o sistema de aluguel de bicicletas vem crescendo em ritmo acelerado, sendo um negócio altamente rentável (EU VOU DE BIKE, 2011). Outra vantagem a ser considerada é que, devido à rotatividade, a bicicleta acaba ficando menos tempo ociosa, aumentando então a eficiência de uso da mesma.

A instalação de pontos de aluguel de bicicleta no Brasil, teve seu início no município do Rio de Janeiro através do Bike Rio em 2011, e espalhou para diversas capitais e cidades, como: Petrolina, Porto Leve e Recife, em Pernambuco; Porto Alegre, no Rio Grande do Sul; e Santos, São Paulo e Sorocaba, em São Paulo (BRASIL, 2014). O Brasil possui o posto de quarto maior produtor mundial de bicicletas. Em 2016, produziu em torno de 2,5 milhões de unidades e, em 2017, possuía uma frota estimada em 70 milhões de bicicletas (ABRACICLO, 2017).

A bicicleta representa o veículo individual mais utilizado no Brasil, tendo como seu nicho principal de utilização os pequenos centros urbanos, classificados como cidades com menos de 50 mil habitantes, sendo esses centros cerca de $90 \%$ das cidades brasileiras (BRASIL, 2007). Já nas cidades de grande porte, existe uma mudança de situação, visto o maior número de oferta de transportes coletivos e a existência de um trânsito consideravelmente mais agressivo. Contudo, devido às regiões periféricas das cidades possuírem um transporte público de menor eficiência e se assemelharem com cidades de médio porte, existe um maior uso de bicicleta nessas áreas (ibid).

Outra importante questão envolvendo o uso da bicicleta, é a sua capacidade de promover o desenvolvimento sustentável das cidades, definido como o desenvolvimento que combine as necessidades das gerações presentes sem comprometimento da capacidade das gerações futuras de suprirem suas próprias demandas (WCED,1987). Os três pilares para alcançar os objetivos supramencionados são, sociedade, meio ambiente e economia, fatores intrinsicamente conectados (ibid). A mudança em qualquer um dos 
pilares causa efeitos diretos nas diretrizes dos demais, sendo essencial a existência de uma economia produtiva capaz de abastecer de forma justa os produtos requeridos pela população para a vida em condições humanas dignas (CHOI, 2014).

Nesse contexto, a mobilidade sustentável pode ser entendida como uma filosofia de planejamento onde o objetivo final é facilitar o uso multifuncional das vias e não mais a maximização do volume de veículos (ibid). No caso brasileiro a questão se deu num momento de desenvolvimento econômico, com altos índices de aumento no número de veículos motorizados, juntamente com limitações das políticas públicas de transporte coletivo (BRASIL, 2017).

A ação padrão para responder ao crescimento do tráfego urbano é a criação de novas vias para atender à nova demanda, contudo isso só alimenta um ciclo vicioso. Com o objetivo de suprimir esse ciclo, foi criado e aprovado no Brasil, através da Lei Federal n 12.587 de 2012, a Política Nacional de Mobilidade Urbana (BRASIL, 2017) seguindo diretrizes como:

- Priorizar o desenvolvimento de transportes não motorizados frente aos motorizados e dos transportes coletivos frente ao individual motorizado;

- Redução dos custos ambientais, econômicos e sociais associados ao deslocamento de pessoas e produtos na cidade;

- Garantia de espaços exclusivos nas vias públicas, voltados a atender os transportes não motorizados e transporte público coletivo;

- Integração entre os diversos modais de transporte;

- Restrições para o acesso e circulação de veículos motorizando em determinados locais e horários.

Em escala local, a locomoção a pé ou pelo uso de bicicleta se tornam muito importantes no conceito de mobilidade sustentável. Ambos os modais são ausentes de emissão de gases poluentes, sendo a caminhada uma forma de aumentar a interação humana e a bicicleta uma forma rápida e barata de se locomover e de promover a integração com o transporte público (CHOI, 2014). O trabalho desenvolvido por Choi (ibid) explorou o conceito de cidade sustentável, com foco principal na aplicação de políticas pró-ciclismo na realidade urbana. A análise do estudo se deu na cidade de Seul, capital da República da Coreia do Sul, e o objetivo foi responder quais seriam os impactos 
gerados pelas políticas cicloviárias, para a criação de uma cidade sustentável, e quais seriam as políticas chaves.

As cidades mais amistosas para ciclistas costumam ter uma divisão modal de bicicletas superior a 30\%. Contudo, para objetivar essa meta deve-se garantir capacidade física, segurança e atratividade para o uso da mesma. Os planejadores atualmente vêm enfrentando dificuldades para incentivar o uso da bicicleta como meio de transporte, e com espaço apropriado. Outro obstáculo tem sido a integração eficiente da infraestrutura cicloviária com os outros modais de transportes (PRESTO, 2010).

Um estudo realizado pelo Departamento de Transportes de Chicago (CDOT, 2017) teve como finalidade planejar o crescimento da malha cicloviária da cidade para 2020. O plano procurou revisar 645 milhas de infraestrutura, de forma a permitir que até mesmo crianças de oito anos pudessem utilizá-las com segurança. Para tanto, foram utilizados três balizadores: estacionamentos para bicicletas a cada meia milha; expandir as malhas cicloviárias em zonas mais densamente habitadas; e aumentar a infraestrutura em zonas com alto índice de usuários de bicicleta, em conjunto com investimentos em regiões com potencial para o aumento de usuários.

Um trabalho conduzido pela Copenhagenize Design Company (2016) voltado para a cidade de Almetyevsk, na Rússia, fez um planejamento para a criação de $50 \mathrm{~km}$ de vias cicláveis ao longo da cidade, cujas metas foram: 10\% da população adotar a bicicleta como seu principal modal de transporte; igual proporção de gêneros entre os ciclistas; $20 \%$ dos estudantes infantis utilizarem a bicicleta como modo de transporte; redução do número de acidentes de pedestres e ciclistas.

\section{METODOLOGIA}

Esta seção apresenta a metodologia desenvolvida para auxiliar os planejadores, durante a seleção das políticas públicas de estímulo às viagens de bicicleta, mais apropriadas às características de cada área de estudo. O fluxograma da figura 1 apresenta a sequência e interdependência das etapas da metodologia de trabalho. 
Figura 1 - Fluxograma da metodologia de trabalho



Fonte: Autores.

\section{Delimitação da área de estudo ( $\left(1^{\mathrm{a}}\right.$ Etapa $)$}

Nesta etapa, o planejador deve delimitar a área de estudo, que pode ser toda a cidade ou áreas menores, tais como, zonas de tráfego, áreas de planejamento, etc., pois, de acordo com os objetivos do estudo, pode ser mais adequado dividir o planejamento em áreas com características relativamente homogêneas.

\section{Seleção das cidades mais amigáveis ao ciclista ( $2^{\mathrm{a}}$ Etapa)}

Nesta etapa da metodologia proposta deve ser feita uma análise das ações tomadas nas cidades que obtiveram sucesso em se tornar amigáveis ao ciclista. Recomenda-se a utilização de rankings ou avaliações promovidas por órgãos competentes ou instituições de pesquisa ligadas à mobilidade urbana e ao uso da bicicleta para selecionar as regiões amigáveis aos ciclistas. Portanto, é importante que a busca por regiões amigáveis aos ciclistas considere rankings e avaliações internacionais. Muitas vezes podemos achar mais de uma solução para o mesmo problema, tendo em vista que conjunturas diferentes implicam em medidas diferentes. Um exemplo é a questão do roubo de bicicletas, onde algumas regiões utilizam bancos de dados para bicicletas achadas e perdidas, e outras regiões utilizam um registro das bicicletas através de uma espécie de chassi.

\section{Listagem das políticas públicas ( $3^{\text {a }}$ Etapa)}

Nesta etapa é criada uma listagem das políticas públicas adotadas pelas cidades selecionadas na $2^{\mathrm{a}}$ etapa desta metodologia. Devem-se listar as políticas que envolvam o incentivo e a melhoria do uso da bicicleta. Uma forma de identificar tais políticas, é através de análise dos planos de mobilidade desenvolvidos por essas cidades. Esta listagem será de fundamental importância para o entendimento das melhores práticas adotadas no mundo. É importante destacar que ações semelhantes podem possuir 
nomenclaturas diferentes, em diferentes cidades. Desta forma, deve-se uniformizar os termos, no sentido de se evitarem repetições.

\section{Análise da incidência das políticas públicas (4ª Etapa)}

Após a listagem das políticas selecionadas, é medida a incidência de cada uma, possibilitando a identificação das práticas mais adotadas. Segundo um estudo realizado pela Clean Air Asia em parceria com UN-Habitat (2013), a decisão de adotar ou não a bicicleta como um modelo de transporte está relacionada a diferentes fatores. Como forma de estabelecer uma relação com as políticas públicas, listadas na $2^{\text {a }}$ etapa da metodologia, tais fatores devem ser agrupados em 5 macrofatores (CITY OF COPENHAGEN, 2011): Tempo de viagem; Sensação de segurança; Conforto ao usuário; Estilo de vida; Experiência de uso. $\mathrm{O}$ quadro 1 apresenta a distribuição dos fatores que influenciam o uso da bicicleta, dentro dos seus respectivos macrofatores.

Quadro 1 - Distribuição dos fatores que influenciam o uso da bicicleta dentro dos macrofatores

\begin{tabular}{|c|c|}
\hline Macro-fator & Fatores \\
\hline \multirow{5}{*}{ Tempo de viagem } & Bike-Sharing System \\
\hline & Integração com o transporte público \\
\hline & Vias adequadas para o ciclista \\
\hline & Interseções adequadas \\
\hline & Conectividade entre as rotas existentes \\
\hline \multirow{6}{*}{ Sensação de segurança } & Sinalização adequada \\
\hline & Sentimento de segurança \\
\hline & Iluminação pública \\
\hline & Comportamento dos motoristas \\
\hline & $\begin{array}{l}\text { Conflito com os demais modais de } \\
\text { transportes }\end{array}$ \\
\hline & Vandalismo das zonas de infraestrutura \\
\hline \multirow{6}{*}{ Conforto ao usuário } & $\begin{array}{l}\text { Presença de lojas para bicicletas perto de } \\
\text { bicicletários e vestiários }\end{array}$ \\
\hline & Estado de conservação das vias \\
\hline & Existência de biciletários \\
\hline & Existência de vestiários \\
\hline & Largura das vias \\
\hline & Existência de mapas \\
\hline Estilo de vida & Cultura de ciclismo \\
\hline \multirow{6}{*}{ Experiência de uso } & Beleza do cenário \\
\hline & Clima \\
\hline & Presença de parques e áreas verdes \\
\hline & Topografia \\
\hline & Poluição do ar \\
\hline & Poluição sonora \\
\hline
\end{tabular}

Fonte: Autores. 


\section{Análise da percepção da população ( $5^{\mathbf{a}}$ Etapa)}

Visando o melhor entendimento da perspectiva do usuário sobre o serviço oferecido, assim como seus anseios, deve ser realizada uma pesquisa de campo com entrevista da população do local de estudo. O modelo a ser adotado para obter este valor do tamanho amostral é o mesmo utilizado por Paiva (2013), conforme a equação 1.

$$
n o=\frac{1}{E o^{2}}
$$

Onde: no - primeira aproximação para o tamanho da amostra;

Eo - erro amostral tolerável.

Quando a população for mais de vinte vezes o tamanho de no, é recomendado adotar o valor calculado para no. Caso contrário, deve-se aplicar a equação 2.

$$
n=\frac{N \times n o}{N+n o}
$$

Onde: $\mathrm{N}$ - tamanho da população;

$\mathrm{n}$ - tamanho da amostra.

Neste estágio, visando avaliar os indicadores individualmente, deve-se utilizar a escala de Lickert, conforme sugerido por Nascimento e Sousa (2015, p.240), que define os pesos, ou os graus de importância, de cada fator apresentado no quadro 1: $5=$ Extremamente importante; 4 = muito importante; 3 = pouco importante; 2 = não muito importante; 1 = sem importância.

\section{Classificação das políticas públicas ( $6^{\mathrm{a}}$ Etapa)}

Nesta etapa pretende-se conhecer a visão de especialistas na área de transportes e planejamento urbano. Para possuir uma variedade mais consistente de informações, recomenda-se abordar especialistas tanto de empresas privadas, como de meios acadêmicos e de instituições públicas, cujas áreas de atuação estejam correlacionadas ao tema. 
Em uma pesquisa fenomenológica, ou seja, pesquisa qualitativa, a fixação da amostra pode se dar de forma aleatória (LARA; MOLINA, 2011) desde que garantam a representatividade. Isso se dá pelo fato de que toda amostra qualitativa não é probabilística, não exigindo o uso de cálculo matemático. Para garantir a representatividade da amostra qualitativa recomenda-se buscar pelo menos um profissional do setor público, privado e acadêmicos, das regiões selecionadas na segunda etapa desta metodologia. Visando trazer uma perspectiva local ao estudo, é interessante buscar, também, especialistas mais regionais, ou seja, do país em que a região de estudo está inserida.

Em seguida, deve-se analisar as percepções da população e dos especialistas, e as práticas adotadas no mundo. Com base na listagem das políticas públicas obtida na $2^{\mathrm{a}}$ etapa desta metodologia, o especialista será orientado a classificar a política pública conforme os fatores apresentados.

\section{Análise de correlações ( $7^{\mathrm{a}}$ Etapa)}

Nesta etapa são analisados alguns fatores relativos às áreas de estudo, selecionadas na primeira etapa, tais como, topografia, densidade demográfica, clima, população, etc. Com base nessa análise é possível fazer uma comparação entre a área de estudo e as áreas mais amigáveis ao ciclista, no sentido de se criar um filtro para a tomada de decisões, de modo a orientar a escolha do planejador. Fatores como frota de bicicleta, quilometragem da malha cicloviária, e distribuição modal, estão associados prioritariamente a resultados de políticas adotadas no passado, pois são indicadores do sucesso de tais políticas. Para harmonizar as escalas dos dados coletados é necessária a normalização dos valores atribuídos. A figura 2 mostra algumas fórmulas capazes de realizar essa tarefa.

Figura 2 - Fórmulas para normalização dos valores atribuídos

\begin{tabular}{|l|l|l|}
\hline Fórmulas de transformação & $\begin{array}{l}\text { Valores normalizados dos } \\
\text { extremos da escala }\end{array}$ & Observações \\
\hline$\left(z_{i}^{k}\right)_{N}=\frac{z_{i}^{k}-z_{\min }^{k}}{z_{\max }^{k}-z_{\min }^{k}}$ & $\begin{array}{l}\text { Máximo }=1 \\
\text { Mínimo }=0\end{array}$ & $\begin{array}{l}\text { Atributos de maximização } \\
\text { Ideal }=1\end{array}$ \\
\hline$\left(z_{i}^{k}\right)_{N}=\frac{z_{\max }^{k}-z_{i}^{k}}{z_{\max }^{k}-z_{\min }^{k}}$ & $\begin{array}{l}\text { Máximo }=0 \\
\text { Mínimo }=1\end{array}$ & $\begin{array}{l}\text { Atributos de minimização } \\
\text { Ideal }=1\end{array}$ \\
\hline$\left(z_{i}^{k}\right)_{N}=\frac{z_{i}^{k}}{z_{\max }^{k}}$ & $\begin{array}{l}\text { Máximo }=1 \\
\text { Mínimo }=z_{\min }^{k} / z_{\max }^{k}\end{array}$ & $\begin{array}{l}\text { Atributos de maximização } \\
\text { Ideal }=1\end{array}$ \\
\hline$\left(z_{i}^{k}\right)_{N}=\frac{z_{\min }^{k}}{z_{i}^{k}}$ & $\begin{array}{l}\text { Máximo }=z_{\max }^{k} / z_{\min }^{k} \\
\text { Mínimo }=1\end{array}$ & $\begin{array}{l}\text { Atributos de minimização } \\
\text { Transformação não-linear }\end{array}$ \\
\hline
\end{tabular}

Fonte: Matos (2018). 
Conforme analisado no trabalho de Spingnardi e Monteiro (2017), a variação de temperatura é o fator ambiental com maior impacto no uso da bicicleta, principalmente em temperaturas extremas, ou seja, tanto muito quentes quanto muito frias. $\mathrm{O}$ intervalo térmico considerado mais confortável para influenciar positivamente os ciclistas está entre $14^{\circ} \mathrm{C}$ e $40^{\circ} \mathrm{C}$ (PHUNG; ROSE, 2008 apud SPINGNARDI; MONTEIRO, 2017). A temperatura ideal para o uso da bicicleta varia entre $20^{\circ} \mathrm{C}$ a $28^{\circ} \mathrm{C}$ (SPINGNARDI; MONTEIRO, 2017). Nesta metodologia recomenda-se utilizar a média anual de cada região, para fins de correlação.

Ainda segundo o estudo de Spingnardi e Monteiro (2017) a precipitação pluvial está diretamente ligada à decisão de usar a bicicleta como modo de transporte. Como a bicicleta no geral é um veículo descoberto, o ciclista fica muito vulnerável à chuva. Visando a correlação, recomenda-se o uso do índice pluviométrico médio anual de cada região.

A densidade demográfica é a razão entre população e a área de uma região, e afeta diretamente todo o sistema de transportes. Como analisado por Goodridge (2001), regiões que possuem alta densidade de moradores, como por exemplo, uma região de prédios, possui maior atratividade para ciclistas do que regiões com casas e baixa densidade demográfica. Essas zonas costumam estar localizadas próximas a locais de destino final, como centros urbanos, tornando a distância de viagem mais acessível aos ciclistas.

De forma a garantir que se está trabalhando com as regiões mais semelhantes, deve-se calcular a distância entre os pontos do gráfico formado. Essa distância deve ser calculada de forma simples através dos valores de $\Delta \mathrm{x}$ e $\Delta \mathrm{y}$, conforme a fórmula exposta na figura 3.

Figura 3 - Fórmula para cálculo da distância entre pontos

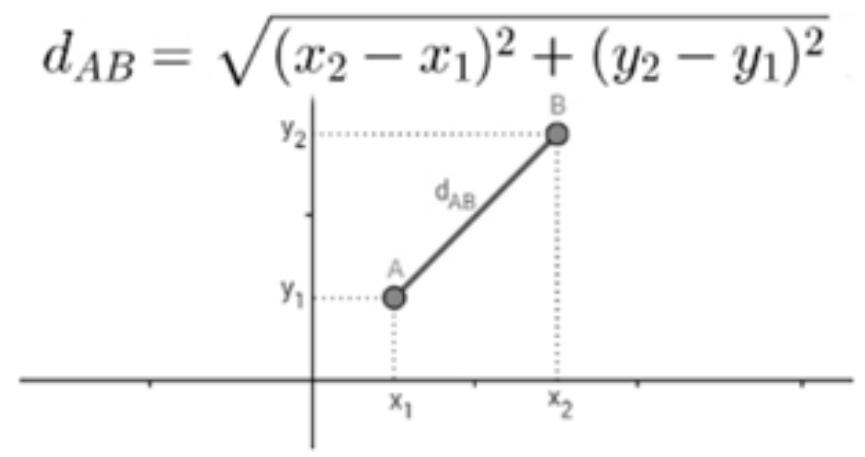

Fonte: Moreira (2018). 
De forma a manter uma boa amostragem qualitativa, recomenda-se a utilização de pelo menos 3 regiões mais semelhantes à região estudada. Sendo assim, pode-se garantir uma gama razoável de políticas.

\section{Seleção das políticas públicas ( $8^{\text {a }}$ Etapa)}

A seleção das políticas públicas é realizada por meio da aplicação de três filtros auxiliares à tomada de decisão. Com base na análise das correlações realizadas na $7^{\mathrm{a}}$ etapa deste trabalho, são selecionadas as regiões que possuem mais similaridades com a área de estudo. Desta forma, podem-se adotar as políticas públicas dessas regiões de referência, para incentivar o uso da bicicleta na área de estudo, conforme exposto na figura 4.

Figura 4 - Exemplo do filtro das correlações

\begin{tabular}{|c|c|c|c|c|c|}
\hline \multirow[b]{2}{*}{ Políticas Públicas } & \multicolumn{2}{|c|}{ Regiões } & \multirow{3}{*}{ Políticas Públicas } & \multirow{2}{*}{\multicolumn{2}{|c|}{ Regiões }} \\
\hline & Região 2 & Região 3 & & & \\
\hline Política 1 & $x$ & $\mathrm{x}$ & & Região 2 & Região 3 \\
\hline Política 2 & $\mathrm{x}$ & & Política 1 & $\mathrm{x}$ & $\mathrm{x}$ \\
\hline Política 3 & $x$ & & Política 2 & $\mathrm{x}$ & \\
\hline Política 4 & $\mathrm{x}$ & $\mathrm{x}$ & Política 3 & $x$ & \\
\hline Política 5 & & & Política 4 & $x$ & $\mathrm{x}$ \\
\hline Política 6 & & $\mathrm{x}$ & Política 6 & & $x$ \\
\hline Política 7 & $\mathrm{x}$ & & Política 7 & $x$ & \\
\hline
\end{tabular}

Fonte: Autores.

Com as respostas do questionário de percepção do público, são definidos os macrofatores mais relevantes. Visando auxiliar essa definição, o planejador deve somar as notas dadas para todos os fatores inseridos no macrofator, e fazer a média. Desta forma, será possível ter um grau de importância referente a cada macrofator. Após tal cálculo, e com base nas políticas selecionadas pelo filtro da correlação, devem-se selecionar as políticas que se enquadram em tal macrofator, conforme ilustrado na figura 5.

Figura 5 - Exemplo do filtro dos macrofatores

\begin{tabular}{|c|c|}
\hline Políticas Públicas & Macrofator 1 \\
\hline Política 1 & $\mathrm{x}$ \\
\hline Política 2 & \\
\hline Política 3 & \\
\hline Política 4 & $\mathrm{x}$ \\
\hline Política 6 & $\mathrm{x}$ \\
\hline
\end{tabular}

Fonte: Autores. 
Visando a tomada final de decisão, a seleção agora se dá pela incidência de cada política pública, medida na $3^{\mathrm{a}}$ etapa desta metodologia. $\mathrm{O}$ tomador de decisão deve priorizar aquela com a maior incidência, conforme ilustra o quadro 2. Neste exemplo, nota-se que o planejador deve dar prioridade à Política 1, em seguida à Política 4, e, por último, à Política 6. Esse processo tem o intuito de identificar a política com maiores chances de sucesso.

Quadro 2 - Exemplo do filtro incidência

\begin{tabular}{|c|c|c|}
\hline Políticas Públicas & Macrofator 1 & Incidência \\
\hline Política 1 & $\mathrm{x}$ & $80 \%$ \\
\hline Política 4 & $\mathrm{x}$ & $60 \%$ \\
\hline Política 6 & $\mathrm{x}$ & $40 \%$ \\
\hline
\end{tabular}

Fonte: Autores

\section{ESTUDO DE CASO}

Neste capítulo a metodologia proposta é testada por meio de um estudo de caso, aplicado ao município de Niterói, no Estado do Rio de Janeiro, com os resultados indicando quais seriam as políticas públicas mais adequadas a essa cidade.

\section{Delimitação da área de estudo}

A cidade de Niterói foi escolhida para este estudo de caso devido aos seus graves problemas de transportes, onde, por exemplo, o tempo de deslocamento nos horários de pico chegam a custar aos motoristas $78 \%$ a mais de tempo do que nos horários com menos trânsito (ALVES, 2018). Além disso, destaca-se que a cidade de Niterói anunciou, recentemente, um pacote de obras no valor de $\mathrm{R} \$ 500$ milhões (ibid), dos quais, $\mathrm{R} \$ 30$ milhões foram destinados para a construção de um trecho de $50 \mathrm{~km}$ de ciclovias, 100 bicicletários abertos e 6 fechados (SODRÉ, 2018).

\section{Seleção das cidades mais amigáveis ao ciclista}

Para este estudo, foi utilizado o Bicycle Friendly Cities Index que é um indicador feito pela Copenhagenize Design Company. Este ranking é feito ao nível municipal e analisa cidades de todo o mundo. O ranking é feito com base em 14 parâmetros: Apoio do poder público; Cultura do uso da bicicleta; Construções adaptadas para o ciclista; Infraestrutura adequada para o ciclista; Programa de aluguel de bicicletas; Divisão dos usuários por gênero; Porcentagem da divisão modal de transportes relativa à bicicleta; 
Crescimento da porcentagem da divisão modal de transportes relativa à bicicleta; Políticas adotadas para o incentivo ao uso da bicicleta; Aceitação social; Ênfase à bicicleta no planejamento urbano; Criação de zonas de trafego baixa velocidade; Existência de bicicletas para carga.

Considerando os 2 biênios mais recentes avaliados pelo Bicycle Friendly Cities Index foram identificadas 24 cidades. As cidades eleitas como mais amigáveis aos ciclistas estão relacionadas no quadro 3 .

Quadro 3 - Ranking no Bicycle Friendly Cities Index nos anos de 2015 e 2017

\begin{tabular}{|c|c|c|c|c|c|}
\hline \multicolumn{3}{|c|}{2015} & \multicolumn{3}{|c|}{2017} \\
\hline Posição & Cidade & País & Posição & Cidade & País \\
\hline 1 & Copenhague & Dinamarca & 1 & Copenhagen & Dinamarca \\
\hline 2 & Amsterdã & Holanda & 2 & Utrecht & Holanda \\
\hline 3 & Utrecht & Holanda & 3 & Amsterdã & Holanda \\
\hline 4 & Strasbourg & França & 4 & Strasbourg & França \\
\hline 5 & Eindhoven & Holanda & 5 & Malmö & Suécia \\
\hline 6 & Malmö & Suécia & 6 & Bordeaux & França \\
\hline 7 & Nantes & França & 7 & Antwerp & Bélgica \\
\hline 8 & Bordeaux & França & 8 & Ljubljana & Eslovênia \\
\hline 9 & Antwerp & Belgica & 9 & Tokyo & Japão \\
\hline 10 & Sevilha & Espanha & 10 & Berlim & Alemanha \\
\hline 11 & Barcebolna & Espanha & 11 & Barcelona & Catalunha \\
\hline 12 & Berlim & Alemanha & 12 & Viena & Áustria \\
\hline 13 & Ljubljana & Eslovênia & 13 & Paris & França \\
\hline 14 & Bueno Aires & Argentina & 14 & Sevilla & Espanha \\
\hline 15 & Dublin & Irlanda & 15 & Munich & Alemanha \\
\hline 16 & Viena & Austria & 16 & Nantes & França \\
\hline 17 & Paris & França & 17 & Hamburg & Alemanha \\
\hline 18 & Minneapolis & EUA & 18 & Hels inki & Finlândia \\
\hline 19 & Hamburgo & Alemanha & 19 & Oslo & Noruega \\
\hline 20 & Montreal & Canadá & 20 & Montreal & Canadá \\
\hline
\end{tabular}

Fonte: Autores.

\section{Listagem das políticas públicas}

Analisando as estratégias para incrementar e melhorar o uso da bicicleta nas cidades, definidas na $2^{\mathrm{a}}$ etapa, foram identificadas 26 políticas públicas principais (quadro $4)$. 
Quadro 4 - Pesquisa com usuário sobre fatores que influenciam o usa da bicicleta

\begin{tabular}{|c|c|}
\hline Políticas públicas & $\begin{array}{l}\text { Taxa de Incidência } \\
(\%)\end{array}$ \\
\hline Construção, melhoria e manutenção de ciclovias e ciclofaixas & $100,0 \%$ \\
\hline Criação e melhoria de estacionamentos para ciclistas & $95,7 \%$ \\
\hline $\begin{array}{l}\text { Campanhas a nível local ou municipal para estimular o uso da bicicleta e o bom } \\
\text { comportamento no trânsito }\end{array}$ & $82,6 \%$ \\
\hline Melhoraria no sistema de estacionamento e na integração com transporte público & $73,9 \%$ \\
\hline Projeto de sinalização horizontal e vertical de trânsito, adequado aos ciclistas & $69,6 \%$ \\
\hline Criação e expansão do sistema de aluguel de bicicletas & $65,2 \%$ \\
\hline Melhoria dos cruzamentos & $60,9 \%$ \\
\hline $\begin{array}{l}\text { Redução do limite de velocidade dos carros em zonas sensíveis, como, por exemplo, } \\
\text { próximo a escolas }\end{array}$ & $52,2 \%$ \\
\hline $\begin{array}{l}\text { Expansão dos serviços ao ciclista, como, bomba de ar para pneus, vestiários e pontos de } \\
\text { informação }\end{array}$ & $47,8 \%$ \\
\hline Criação de pontes e túneis para ciclistas & $43,5 \%$ \\
\hline Aulas de como andar de bicicleta e educação no trânsito para crianças e adultos & $39,1 \%$ \\
\hline Construção de vias expressas para bicicletas & $39,1 \%$ \\
\hline Criação de rotas turísticas & $34,8 \%$ \\
\hline Utilização de pavimentação lisa & $34,8 \%$ \\
\hline $\begin{array}{l}\text { Informações sobre as melhores rotas através de Sistemas de Posicionamento Global ou } \\
\text { Global Positioning System (GPS) }\end{array}$ & $30,4 \%$ \\
\hline $\begin{array}{l}\text { Estímulo à criação de infraestrutura para o ciclista nos locais de trabalho ou nas } \\
\text { proximidades }\end{array}$ & $26,1 \%$ \\
\hline $\begin{array}{l}\text { Criação de restrições ao estacionamento e ao acesso de carros em áreas centrais da } \\
\text { cidade }\end{array}$ & $26,1 \%$ \\
\hline Alargamento das ciclovias onde há congestionamento de bicicletas & $21,7 \%$ \\
\hline Criação de rotas mais seguras para escolas e faculdades & $21,7 \%$ \\
\hline $\begin{array}{l}\text { Combate ao roubo de bicicletas através de medidas como, cadastro das bicicletas e } \\
\text { informativos sobre bicicletas localizadas }\end{array}$ & $21,7 \%$ \\
\hline Estímulo ao uso de bicicletas elétricas & $17,4 \%$ \\
\hline Ordenamento de canteiros de obras para manter o fluxo das ciclovias & $8,70 \%$ \\
\hline $\begin{array}{l}\text { Adoção de modelos inteligentes de estacionamentos, como, o P-route cycle, e o } \\
\text { mapeamento dos estacionamentos por Sistemas de Informações Geográficas (SIG) }\end{array}$ & $8,70 \%$ \\
\hline Semáforos com contagem de tempo, específicos para bicicletas & $8,70 \%$ \\
\hline Estímulo financeiro para a compra de bicicletas especiais para famílias necessitadas & $8,70 \%$ \\
\hline Criação de uma plataforma online para localizar bicicletas perdidas ou roubadas & $4,35 \%$ \\
\hline
\end{tabular}

Fonte: Autores.

\section{Análise da incidência das políticas públicas}

O quadro 4 também expõe a incidência com que as políticas adotadas pelas regiões amigáveis ao ciclista foram adotadas.

\section{Análise da percepção da população}

Para este trabalho foi adotada a população do município de Niterói, estimada pelo IBGE, para o ano de 2016, de 497.883 habitantes. Assim, através da equação 1, o valor de no será de 100 elementos amostrais para um grau de confiança de 90\%. Como o tamanho da população é mais de 20 vezes o valor de no, não será necessário o cálculo do valor de n. Para a formulação e aplicação do questionário foi utilizada a ferramenta computacional Google Forms. A pesquisa alcançou um total de 100 respostas, e o fator considerado mais relevante para a população foi o sentimento de segurança, com uma nota média de 4,63. Já o fator considerado menos importante foi a beleza do cenário, com 
nota média de 2,72. As figuras 6 e 7 mostram como foram distribuídos os votos para ambos os fatores.

Figura 6 - Grau de importância (de 1, sem importância, a 5, extremamente importante) do fator Sentimento de Segurança, na percepção do usuário de bicicleta



Fonte: Autores.

Figura 7 - Grau de importância (de 1, sem importância, a 5, extremamente importante) do fator Beleza do Cenário, na percepção do usuário de bicicleta

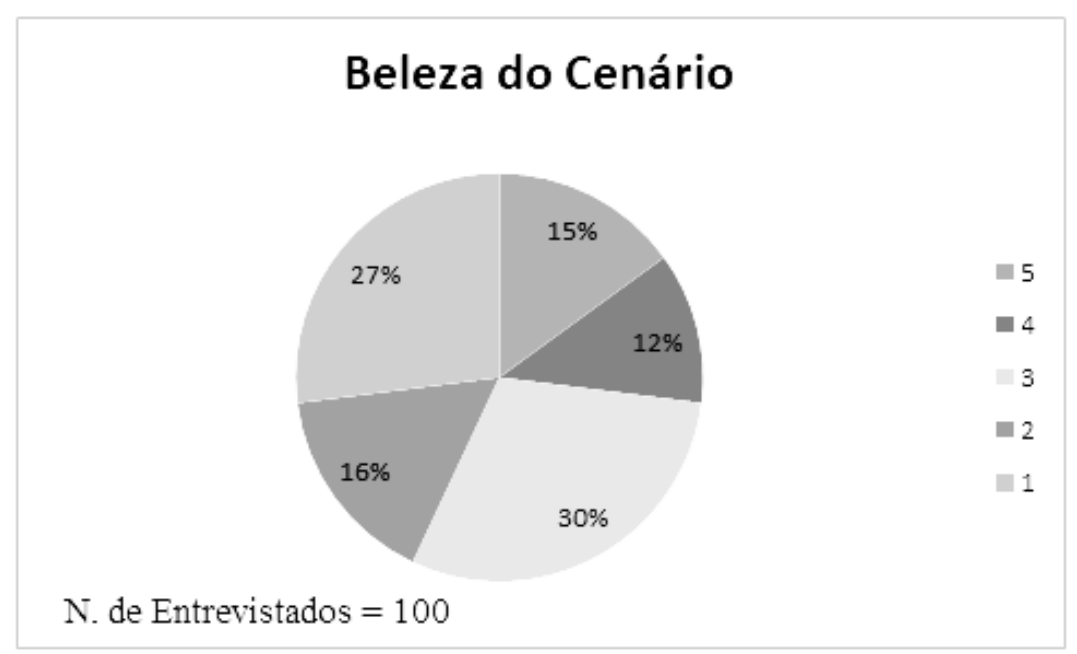

Fonte: Autores.

A escala dos graus de importância, conforme descrito na $5^{\text {a }}$ etapa da metodologia proposta, foi: 5 = Extremamente importante; 4 = muito importante; $3=$ pouco importante; 2 = não muito importante; 1 = sem importância. A tabela 1 ilustra melhor os resultados desta pesquisa, assim como a distribuição dos fatores que influenciam o uso da bicicleta, dentro dos seus respectivos macrofatores. 
Tabela 1 - Nota média por macrofator

\begin{tabular}{|c|c|c|c|}
\hline Macrofator & Fatores & $\begin{array}{l}\text { Nota média por } \\
\text { fator isolado }\end{array}$ & $\begin{array}{l}\text { Nota média por } \\
\text { macrofator }\end{array}$ \\
\hline \multirow{5}{*}{$\begin{array}{l}\text { Tempo de } \\
\text { Viagem }\end{array}$} & Sistema de Compartilhamento de bicicletas & 3,22 & \multirow{5}{*}{3,95} \\
\hline & Integração com o transporte público & 3,89 & \\
\hline & Vias adequadas para o ciclista & 4,51 & \\
\hline & Interseções & 3,85 & \\
\hline & Conectividade entre as rotas existentes & 4,29 & \\
\hline \multirow{6}{*}{$\begin{array}{l}\text { Sensação de } \\
\text { Segurança }\end{array}$} & Sinalização adequada & 4,34 & \multirow{6}{*}{4,43} \\
\hline & Sentimento de segurança & 4,63 & \\
\hline & \|uminação pública das vias & 4,55 & \\
\hline & Comportamento dos motoristas & 4,59 & \\
\hline & Conflito com os demais modais de transportes & 4,27 & \\
\hline & Depredação da infraestrutura cicloviária & 4,21 & \\
\hline \multirow{6}{*}{$\begin{array}{l}\text { Conforto ao } \\
\text { Usuário }\end{array}$} & $\begin{array}{l}\text { Presença de lojas para bicicleta perto de } \\
\text { bicicletários e vestiários }\end{array}$ & 3,77 & \multirow{6}{*}{3,78} \\
\hline & Estado de conservação das vias & 4,32 & \\
\hline & Existência de bicicletánios & 4,29 & \\
\hline & Existência de vestiários & 2,84 & \\
\hline & Largura das vias & 4,09 & \\
\hline & Existência de mapas com as rotas cicloviárias & 3,38 & \\
\hline Estilo de vida & Cultura de ciclismo & 3,91 & 3,91 \\
\hline \multirow{6}{*}{$\begin{array}{l}\text { Experiência de } \\
\text { uso }\end{array}$} & Beleza do cenário & 2,72 & \multirow{6}{*}{3,34} \\
\hline & Clima & 3,86 & \\
\hline & Presença de parques e áreas verdes & 3,33 & \\
\hline & Terreno majoritariamente plano & 3,59 & \\
\hline & Polvição do ar & 3,35 & \\
\hline & Polvição sonora & 3,17 & \\
\hline
\end{tabular}

Fonte: Autores.

\section{Classificação das políticas públicas}

Para esta etapa da metodologia foram consultados especialistas das 24 cidades selecionadas na $2^{\text {a }}$ etapa da metodologia, quadro 3, e também as cidades de São Paulo, Rio de Janeiro e Brasília. A escolha dessas três capitais se deu pelo fato de que apenas essas três cidades juntas acumulam $45,2 \%$ de toda a malha cicloviária das capitais brasileiras (VELASCO; REIS, 2017). Foram contabilizadas 9 respostas, sendo 3 especialistas nacionais, e 6 internacionais, conforme apresenta a quadro 5.

Quadro 5 - Origem e esfera de atuação dos especialistas

\begin{tabular}{cll}
\hline Especialista & Localização & Esfera de atuação \\
\hline 1 & Berlim, Alemanha & Universidade \\
2 & Sevilha, Espanha & Universidade \\
3 & Copenhague, Dinamarca & Prefeitura \\
4 & Malmo, Suécia & Prefeitura \\
5 & Amsterdã, Holanda & Universidade \\
6 & Helsinki, Finland & Prefeitura \\
7 & Brasília, Brasil & Universidade \\
8 & Rio de Janeiro, Brasil & Universidade \\
9 & Brasília, Brasil & Universidade \\
\hline
\end{tabular}

Fonte: Autores. 
Com base nas respostas dos especialistas, foi elaborado o quadro 6. Destaca-se que, seguindo a metodologia proposta, os macrofatores selecionados por um único especialista, para uma determinada política pública, foram desconsiderados.

Quadro 6 - Interveniência das políticas públicas sobre os macrofatores

\begin{tabular}{|c|c|c|c|c|c|}
\hline \multirow[b]{2}{*}{ Políticas Públicas } & \multicolumn{5}{|c|}{ Macrofatores } \\
\hline & $\begin{array}{l}\text { Tempo de } \\
\text { Viagem }\end{array}$ & $\begin{array}{c}\begin{array}{c}\text { Sensação } \\
\text { de }\end{array} \\
\text { Segurança }\end{array}$ & $\begin{array}{c}\text { Conforto ao } \\
\text { usuário }\end{array}$ & $\begin{array}{l}\text { Estilo de } \\
\text { vida }\end{array}$ & $\begin{array}{l}\text { Experiência } \\
\text { de uso }\end{array}$ \\
\hline $\begin{array}{l}\text { Construção, melhoria e manutenção de } \\
\text { ciclovias e ciclofaixas }\end{array}$ & $x$ & $x$ & $x$ & $x$ & \\
\hline Criação e melhoria dos estacionamentos & $x$ & $x$ & $x$ & & \\
\hline $\begin{array}{l}\text { Campanhas para o estímulo ao uso da } \\
\text { bicicleta e ao bom comportamento no } \\
\text { trânsito }\end{array}$ & & $\mathrm{x}$ & $x$ & $\mathrm{x}$ & $\mathrm{x}$ \\
\hline $\begin{array}{l}\text { Criação e expansão do sistema de aluguel } \\
\text { de bicicletas }\end{array}$ & $x$ & & $x$ & $x$ & $\mathrm{x}$ \\
\hline Melhoria dos cruzamentos & $x$ & $x$ & $x$ & & \\
\hline $\begin{array}{l}\text { Projeto de sinalização horizontal e vertical } \\
\text { de trânsito, adequado aos ciclistas }\end{array}$ & $x$ & $x$ & $x$ & & \\
\hline $\begin{array}{l}\text { Melhoria do sistema de estacionamento e } \\
\text { integração com o transporte público }\end{array}$ & $x$ & & $x$ & & $x$ \\
\hline $\begin{array}{l}\text { Redução do limite de velocidade de carros } \\
\text { em lugares sensíveis, como próximo a } \\
\text { escolas }\end{array}$ & $x$ & $\mathrm{x}$ & & & \\
\hline $\begin{array}{l}\text { Expansão dos serviços ao ciclista, como, } \\
\text { bombas de ar para pneus, vestiários e } \\
\text { informações }\end{array}$ & & $x$ & $x$ & $x$ & $x$ \\
\hline Criação de pontes e túneis & $x$ & $x$ & $x$ & & \\
\hline $\begin{array}{l}\text { Aula de como andar de bicicleta e } \\
\text { educação no trânsito }\end{array}$ & & $x$ & & $x$ & $x$ \\
\hline Criação de rotas turísticas & & & $x$ & $x$ & $x$ \\
\hline $\begin{array}{l}\text { Construção de vias expressas para } \\
\text { bicicletas }\end{array}$ & $x$ & $x$ & $x$ & $x$ & \\
\hline Utilização de pavimentação lisa & $x$ & $x$ & $x$ & & \\
\hline $\begin{array}{l}\text { Informações sobre melhores rotas através } \\
\text { de GPS }\end{array}$ & $x$ & & $x$ & & \\
\hline $\begin{array}{l}\text { Estímulo à criação de infraestrutura nos } \\
\text { locais de trabalho ou proximidades }\end{array}$ & $x$ & $x$ & $x$ & $x$ & \\
\hline $\begin{array}{l}\text { Restingir o acesso de carros ao centro da } \\
\text { cidades }\end{array}$ & $x$ & $\mathrm{x}$ & $x$ & $\mathrm{x}$ & $x$ \\
\hline $\begin{array}{l}\text { Alargamento das ciclovias onde há } \\
\text { congestionamento de bicicletas }\end{array}$ & $x$ & $\mathrm{x}$ & $x$ & & \\
\hline $\begin{array}{l}\text { Criação de rotas mais segura para as } \\
\text { escolas }\end{array}$ & & $x$ & $x$ & $x$ & \\
\hline Estímulo ao uso de bicicletas elétricas & $x$ & & $x$ & $x$ & $x$ \\
\hline $\begin{array}{l}\text { Estímulo financeiro para a compra de } \\
\text { bicicletas especiais para familias } \\
\text { necessitadas }\end{array}$ & & $x$ & & $x$ & $x$ \\
\hline $\begin{array}{l}\text { Criação de uma plataforma online para } \\
\text { localizar bicicletas perdidas ou roubadas }\end{array}$ & & $x$ & $x$ & & \\
\hline $\begin{array}{l}\text { Combate ao roubo de bicicletas através de } \\
\text { medidas como, cadastro das bicicletas }\end{array}$ & & $x$ & $x$ & & \\
\hline $\begin{array}{l}\text { Ordenamento dos canteiros de obra para } \\
\text { manter fluxo das ciclovias }\end{array}$ & $x$ & $x$ & $x$ & & \\
\hline $\begin{array}{l}\text { Modelos inteligentes de estacionamento } \\
\text { com mapeamento por SIG }\end{array}$ & $x$ & & $x$ & $x$ & \\
\hline $\begin{array}{l}\text { Semáforos com contagem de tempo para } \\
\text { bicicletas }\end{array}$ & $x$ & $x$ & $x$ & & \\
\hline
\end{tabular}

Fonte: Autores. 


\section{Análise das correlações}

Como limites superior e inferior para a normalização dos dados, foi usada como referência a temperatura de $-45^{\circ} \mathrm{C}$, da cidade de Oymyakon, na Rússia (BBC, 2018), e de $51{ }^{\circ} \mathrm{C}$, da cidade de Karachi, no Kuwait, e da cidade Ahvaz, no Irã (BIRCH, 2015). Tanto os dados de temperatura, quanto de precipitação, foram obtidos através da plataforma World Weather Online (2018), onde foi possível coletar as médias para cada região estudada neste trabalho, conforme apresentado na tabela 2.

Tabela 2 - Índice climático normalizado

\begin{tabular}{lccccc}
\hline \multicolumn{1}{c}{ Cidade } & $\begin{array}{c}\text { Temp. Média } \\
\text { Anual }\left({ }^{\circ} \mathbf{C}\right)\end{array}$ & $\begin{array}{c}\text { Temp. } \\
\text { Média } \\
\text { Normalizada }\end{array}$ & $\begin{array}{c}\text { Índice } \\
\text { Pluviométrico } \\
\text { Médio Anual } \\
(\mathbf{m m} / \mathbf{m e ̂ s})\end{array}$ & $\begin{array}{c}\text { Índice } \\
\text { Pluviométrico } \\
\text { Normalizado }\end{array}$ & $\begin{array}{c}\text { Índice } \\
\text { Climático } \\
\text { Normalizado }\end{array}$ \\
\hline Niterói & 27,1 & 0,743 & 61,0 & 0,488 & 0,615 \\
Copenhague & 10,3 & 0,570 & 70,0 & 0,559 & 0,565 \\
Utrecht & 13,1 & 0,599 & 83,4 & 0,667 & 0,633 \\
Amsterdã & 12,8 & 0,596 & 112,9 & 0,902 & 0,749 \\
Strasbourg & 13,7 & 0,605 & 89,6 & 0,716 & 0,661 \\
Malmö & 10,0 & 0,567 & 67,8 & 0,542 & 0,554 \\
Bordeaux & 14,3 & 0,611 & 106,0 & 0,847 & 0,729 \\
Antwerp & 13,5 & 0,603 & 98,8 & 0,789 & 0,696 \\
Ljubljana & 13,9 & 0,607 & 102,5 & 0,820 & 0,713 \\
Tokyo & 18,8 & 0,658 & 110,9 & 0,887 & 0,772 \\
Berlim & 12,3 & 0,590 & 68,9 & 0,551 & 0,570 \\
Barcelona & 18,8 & 0,657 & 65,1 & 0,520 & 0,589 \\
Viena & 13,9 & 0,607 & 64,5 & 0,515 & 0,561 \\
Paris & 14,1 & 0,609 & 97,9 & 0,783 & 0,696 \\
Sevilla & 21,4 & 0,685 & 63,3 & 0,506 & 0,595 \\
Munich & 11,6 & 0,583 & 102,4 & 0,818 & 0,701 \\
Nantes & 14,1 & 0,609 & 90,1 & 0,720 & 0,665 \\
Hamburg & 11,3 & 0,580 & 101,7 & 0,813 & 0,696 \\
Helsinki & 6,8 & 0,534 & 83,3 & 0,666 & 0,600 \\
Oslo & 5,2 & 0,517 & 125,1 & 1,000 & 0,759 \\
Montreal & 8,0 & 0,546 & 120,8 & 0,966 & 0,756 \\
\hline
\end{tabular}

Fonte: Autores.

A tabela 3 apresenta os índices demográficos normalizados para cada cidade em análise. 
Tabela 3 - Índice demográfico normalizado

\begin{tabular}{lcccc}
\hline \multicolumn{1}{c}{ Cidade } & $\begin{array}{c}\text { População } \\
(\mathbf{h a b})\end{array}$ & $\begin{array}{c}\text { Área } \\
\left(\mathbf{k m}^{2}\right)\end{array}$ & $\begin{array}{c}\text { Densidade Populacional } \\
\left(\mathbf{h a b} / \mathbf{k m}^{2}\right)\end{array}$ & $\begin{array}{c}\text { Dens. Pop. } \\
\text { Normalizado }\end{array}$ \\
\hline Niterói & 497.833 & 133,92 & 3.717 & 0,175 \\
Copenhague & 613.288 & 86,39 & 7.099 & 0,334 \\
Utrecht & 338.480 & 99,21 & 3.412 & 0,160 \\
Amsterdã & 851.573 & 219,32 & 3.883 & 0,183 \\
Strasbourg & 277.270 & 78,27 & 3.542 & 0,167 \\
Malmö & 342.908 & 155,40 & 2.207 & 0,104 \\
Bordeaux & 250.776 & 49,36 & 5.081 & 0,239 \\
Antwerp & 520.504 & 204,51 & 2.545 & 0,120 \\
Ljubljana & 279.756 & 163,80 & 1.708 & 0,080 \\
Tokyo & 12.770 .000 & $1.457,30$ & 8.763 & 0,412 \\
Berlim & 3.711 .930 & 891,70 & 4.163 & 0,196 \\
Barcelona & 1.620 .809 & 101,90 & 15.906 & 0,748 \\
Viena & 1.889 .083 & 414,65 & 4.556 & 0,214 \\
Paris & 2.240 .621 & 105,40 & 21.258 & 1,000 \\
Sevilla & 703.021 & 140,00 & 5.022 & 0,236 \\
Munich & 1.464 .301 & 310,43 & 4.717 & 0,222 \\
Nantes & 303.382 & 65,19 & 4.654 & 0,219 \\
Hamburg & 1.805 .316 & 755,00 & 2.391 & 0,112 \\
Helsinki & 642.045 & 672,08 & 955 & 0,045 \\
Oslo & 1.997 .599 & 454,00 & 4.400 & 0,207 \\
Montreal & 1.704 .694 & 365,13 & 4.669 & 0,220 \\
\hline
\end{tabular}

Fonte: Autores.

Conforme apontado na tabela 4, as cinco regiões mais semelhantes a Niterói são as cidades de Utrecht, Bordeaux, Barcelona, Viena e Paris.

Tabela 4 - Dispersão dos dados

\begin{tabular}{lccc}
\hline Cidade & $\begin{array}{c}\text { Índice Populacional } \\
\text { Normalizado }\end{array}$ & $\begin{array}{c}\text { Índice Climático } \\
\text { Normalizado }\end{array}$ & $\begin{array}{c}\text { Distância } \\
\text { entre pontos }\end{array}$ \\
\hline Niterói & 0,175 & 0,615 & - \\
Copenhague & 0,615 & 0,565 & 0,443 \\
Utrecht & 0,565 & 0,633 & 0,390 \\
Amsterdã & 0,633 & 0,749 & 0,477 \\
Strasbourg & 0,749 & 0,661 & 0,576 \\
Malmö & 0,661 & 0,554 & 0,490 \\
Bordeaux & 0,554 & 0,729 & 0,396 \\
Antwerp & 0,729 & 0,696 & 0,560 \\
Ljubljana & 0,696 & 0,713 & 0,530 \\
Tokyo & 0,713 & 0,772 & 0,561 \\
Berlim & 0,772 & 0,570 & 0,599 \\
Barcelona & 0,570 & 0,589 & 0,396 \\
Viena & 0,589 & 0,561 & 0,417 \\
Paris & 0,561 & 0,696 & 0,395 \\
Sevilla & 0,696 & 0,595 & 0,521 \\
Munich & 0,595 & 0,701 & 0,429 \\
Nantes & 0,701 & 0,665 & 0,528 \\
Hamburg & 0,665 & 0,696 & 0,496 \\
Helsinki & 0,696 & 0,600 & 0,522 \\
Oslo & 0,600 & 0,759 & 0,448 \\
Montreal & 0,759 & 0,756 & 0,600 \\
\hline & & & \\
\hline
\end{tabular}

Fonte: Autores. 


\section{Seleção das políticas públicas}

Com base nas regiões selecionadas na $7^{\text {a }}$ etapa da metodologia, foi aplicado o primeiro filtro na seleção das políticas públicas, conforme apresentado no quadro 7. Com esse filtro, houve uma redução de 26 políticas públicas, para 20.

\section{Quadro 7 - Filtro das correlações}

\begin{tabular}{|c|c|c|c|c|c|}
\hline Políticas Públicas & Utrecht & Bordeaux & Barcelona & Viena & Paris \\
\hline Criação de pontes e túneis & $\mathrm{x}$ & & & & \\
\hline Construção de vias expressas para bicicletas & & $\mathrm{x}$ & & & \\
\hline $\begin{array}{l}\text { Construção, melhoria e manutenção de ciclovias e } \\
\text { ciclofaixas }\end{array}$ & $\mathrm{x}$ & $\mathrm{x}$ & $\mathrm{x}$ & $\mathrm{x}$ & $\mathrm{x}$ \\
\hline Melhoria dos cruzamentos & $\mathrm{x}$ & & $\mathrm{x}$ & & \\
\hline $\begin{array}{l}\text { Alargamento das ciclovias onde há congestionamento de } \\
\text { bicicletas }\end{array}$ & $\mathrm{x}$ & & & $\mathrm{x}$ & \\
\hline Criação e expansão de um sistema de aluguel de bicicletas & & $\mathrm{x}$ & $\mathrm{x}$ & $\mathrm{x}$ & $\mathrm{x}$ \\
\hline Criação e melhoria de estacionamentos & $\mathrm{x}$ & $\mathrm{x}$ & $\mathrm{x}$ & $\mathrm{x}$ & $\mathrm{x}$ \\
\hline $\begin{array}{l}\text { Modelos inteligentes de estacionamento, como, } P \text {-route } \\
\text { bicycle, e Mapeamento dos estacionamentos por SIG }\end{array}$ & $\mathrm{x}$ & & & & \\
\hline Informações sobre melhores rotas através de GPS & & & & $\mathrm{x}$ & \\
\hline $\begin{array}{l}\text { Redução do limite de velocidade dos carros em locais } \\
\text { sensíveis, como próximos a escolas }\end{array}$ & $\mathrm{x}$ & & $\mathrm{x}$ & $\mathrm{x}$ & $\mathrm{x}$ \\
\hline $\begin{array}{l}\text { Projeto de sinalização horizontal e vertical de trânsito, } \\
\text { adequado aos ciclistas }\end{array}$ & $\mathrm{x}$ & $\mathrm{x}$ & $\mathrm{x}$ & $\mathrm{x}$ & $\mathrm{x}$ \\
\hline Semáforos com contagem de tempo para bicicletas & $\mathrm{x}$ & & & & \\
\hline $\begin{array}{l}\text { Melhorias no sistema de estacionamento e integração com o } \\
\text { transporte público }\end{array}$ & $\mathrm{x}$ & $\mathrm{x}$ & & $\mathrm{x}$ & $\mathrm{x}$ \\
\hline \multicolumn{6}{|l|}{ Estímulo ao uso de bicicletas elétricas } \\
\hline $\begin{array}{l}\text { Estímulo à criação de infraestrutura para o ciclista nos } \\
\text { locais de trabalho e proximidades }\end{array}$ & & $\mathrm{x}$ & $\mathrm{x}$ & & \\
\hline $\begin{array}{l}\text { Campanhas a nível local ou municipal para o estímulo do } \\
\text { uso da bicicleta e ao bom comportamento no trânsito }\end{array}$ & & $\mathrm{x}$ & $\mathrm{x}$ & $\mathrm{x}$ & $\mathrm{x}$ \\
\hline $\begin{array}{l}\text { Aulas de como andar de bicicleta e educação no trânsito em } \\
\text { escolas locais }\end{array}$ & & & $\mathrm{x}$ & & \\
\hline $\begin{array}{l}\text { Expansão dos serviços ao ciclista, como, bombas de ar para } \\
\text { os pneus, vestiários e informações }\end{array}$ & & $\mathrm{x}$ & & & $\mathrm{x}$ \\
\hline $\begin{array}{l}\text { Combate ao roubo de bicicletas através de medidas como } \\
\text { cadastro das bicicletas e informação sobre bicicletas } \\
\text { encontradas }\end{array}$ & & & & $\mathrm{x}$ & \\
\hline $\begin{array}{l}\text { Estímulo financeiro para a compra de bicicletas especiais } \\
\text { para famílias necessitadas }\end{array}$ & & $\mathrm{x}$ & & & \\
\hline
\end{tabular}

Fonte: Autores.

Com base nos impactos das políticas públicas sobre os macrofatores, medidos na $6^{\text {a }}$ etapa da metodologia, e nos macrofatores mais sensíveis à população da cidade de Niterói, foi aplicado o segundo filtro para a seleção das políticas públicas, conforme 
apresentado no quadro 8. Com esse filtro houve uma redução de 20 políticas públicas, para 15.

Quadro 8 - Filtro dos macrofatores

\begin{tabular}{|c|c|}
\hline Políticas Públicas & Sensação de Segurança \\
\hline Criação de pontes e túneis & $\mathrm{x}$ \\
\hline Construção de vias expressas para bicicletas & $\mathrm{x}$ \\
\hline $\begin{array}{l}\text { Construção, melhoria e manutenção de ciclovias e } \\
\text { ciclofaixas }\end{array}$ & $\mathrm{x}$ \\
\hline Melhoria dos cruzamentos & $\mathrm{x}$ \\
\hline $\begin{array}{l}\text { Alargamento das ciclovias onde há congestionamento } \\
\text { de bicicletas }\end{array}$ & $\mathrm{x}$ \\
\hline \multicolumn{2}{|l|}{$\begin{array}{l}\text { Criação e expansão de um sistema de aluguel de } \\
\text { bicicletas }\end{array}$} \\
\hline Criação e melhoria de estacionamentos & $\mathrm{x}$ \\
\hline \multicolumn{2}{|l|}{$\begin{array}{l}\text { Modelos inteligentes de estacionamento, como, } P \text {-route } \\
\text { bicycle, e Mapeamento dos estacionamentos por SIG }\end{array}$} \\
\hline \multicolumn{2}{|l|}{ Informações sobre melhores rotas através de GPS } \\
\hline $\begin{array}{l}\text { Redução do limite de velocidade dos carros em locais } \\
\text { sensíveis, como, próximos a escolas }\end{array}$ & $\mathrm{x}$ \\
\hline $\begin{array}{l}\text { Projeto de sinalização horizontal e vertical de trânsito, } \\
\text { adequado aos ciclistas }\end{array}$ & $\mathrm{x}$ \\
\hline Semáforos com contagem de tempo para bicicletas & $\mathrm{x}$ \\
\hline \multicolumn{2}{|l|}{$\begin{array}{l}\text { Melhorias no sistema de estacionamento e na integração } \\
\text { com o transporte público }\end{array}$} \\
\hline \multicolumn{2}{|l|}{ Estímulo ao uso de bicicletas elétricas } \\
\hline $\begin{array}{l}\text { Estímulo à criação de infraestrutura para o ciclista nos } \\
\text { locais de trabalho e proximidades }\end{array}$ & $\mathrm{x}$ \\
\hline $\begin{array}{l}\text { Campanhas a nível local ou municipal para o estímulo } \\
\text { do uso da bicicleta e ao bom comportamento no trânsito }\end{array}$ & $\mathrm{x}$ \\
\hline $\begin{array}{l}\text { Aulas de como andar de bicicleta e educação no trânsito } \\
\text { em escolas locais }\end{array}$ & $\mathrm{x}$ \\
\hline $\begin{array}{l}\text { Expansão dos serviços ao ciclista, como, bombas de ar } \\
\text { para os pneus, vestiários e informações }\end{array}$ & $\mathrm{x}$ \\
\hline $\begin{array}{l}\text { Combate ao roubo de bicicletas através de medidas } \\
\text { como, cadastro das bicicletas e informação sobre } \\
\text { bicicletas encontradas }\end{array}$ & $\mathrm{x}$ \\
\hline $\begin{array}{l}\text { Estímulo financeiro para a compra de bicicletas } \\
\text { especiais para famílias necessitadas }\end{array}$ & $\mathrm{x}$ \\
\hline
\end{tabular}

Fonte: Autores.

Com base no cálculo da incidência das políticas públicas na seção 4.5 deste trabalho, foi aplicado o terceiro filtro na seleção das políticas públicas como mostra a tabela 5. Com esse filtro o tomador de decisão poderá criar uma ordem sobre quais políticas públicas ele deve implantar para melhorar o uso da bicicleta na cidade. 
Tabela 5 - Filtro de incidência

\begin{tabular}{|c|c|}
\hline Políticas Públicas & Incidência \\
\hline $\begin{array}{l}\text { Construção, melhoria e manutenção de ciclovias e } \\
\text { ciclofaixas }\end{array}$ & $100,0 \%$ \\
\hline Criação e melhoria de estacionamentos & $95,7 \%$ \\
\hline $\begin{array}{l}\text { Campanhas a nível local ou municipal para o estímulo do } \\
\text { uso da bicicleta e ao bom comportamento no trânsito }\end{array}$ & $82,6 \%$ \\
\hline $\begin{array}{l}\text { Projeto de sinalização horizontal e vertical de trânsito, } \\
\text { adequado aos ciclistas }\end{array}$ & $69,6 \%$ \\
\hline Melhoria dos cruzamentos & $60,9 \%$ \\
\hline $\begin{array}{l}\text { Redução do limite de velocidade dos carros em locais } \\
\text { sensíveis, como próximo a escolas }\end{array}$ & $52,2 \%$ \\
\hline $\begin{array}{l}\text { Expansão dos serviços ao ciclista, como, bombas de ar } \\
\text { para os pneus, vestiários e informações }\end{array}$ & $47,8 \%$ \\
\hline Criação de pontes e túneis & $43,5 \%$ \\
\hline Construção de vias expressas para bicicletas & $39,1 \%$ \\
\hline $\begin{array}{l}\text { Aulas de como andar de bicicleta e educação no trânsito } \\
\text { em escolas locais }\end{array}$ & $39,1 \%$ \\
\hline $\begin{array}{l}\text { Estímulo à criação de infraestrutura para o ciclista nos } \\
\text { locais de trabalho e proximidades }\end{array}$ & $26,1 \%$ \\
\hline $\begin{array}{l}\text { Alargamento das ciclovias onde há congestionamento de } \\
\text { bicicletas }\end{array}$ & $21,7 \%$ \\
\hline $\begin{array}{l}\text { Combate ao roubo de bicicletas através de medidas } \\
\text { como, cadastro das bicicletas e informação sobre } \\
\text { bicicletas encontradas }\end{array}$ & $21,7 \%$ \\
\hline Semáforos com contagem de tempo para bicicletas & $8,7 \%$ \\
\hline $\begin{array}{l}\text { Estímulo financeiro para a compra de bicicletas especiais } \\
\text { para famílias necessitadas }\end{array}$ & $8,7 \%$ \\
\hline
\end{tabular}

Fonte: Autores.

\section{ANÁLISE DOS RESULTADOS}

Ao se analisarem os planos de mobilidade voltados para o uso da bicicleta, e suas políticas públicas, foi possível notar a grande incidência de três, em particular:

- Construção, melhoria e manutenção de ciclovias e ciclofaixas (100\%);

- Criação e melhoria de estacionamentos para bicicletas (95,7\%);

- Campanhas para o estímulo ao uso da bicicleta e ao bom comportamento no trânsito $(82,6 \%)$.

Dessa forma, ressalta-se a importância da aplicação de tais políticas pelo planejador. A aplicação da pesquisa de percepção à população local, possibilitou a descoberta de questões importantes. Quando questionados como se classificariam em 
relação ao uso da bicicleta, $48 \%$ dos usuários responderam possuir vontade de usar a bicicleta, porém possuem preocupações relativas à segurança, indicando uma grande demanda reprimida por parte da população. Essa situação é ilustrada pela figura 8.

Figura 8 - Tipo de ciclista

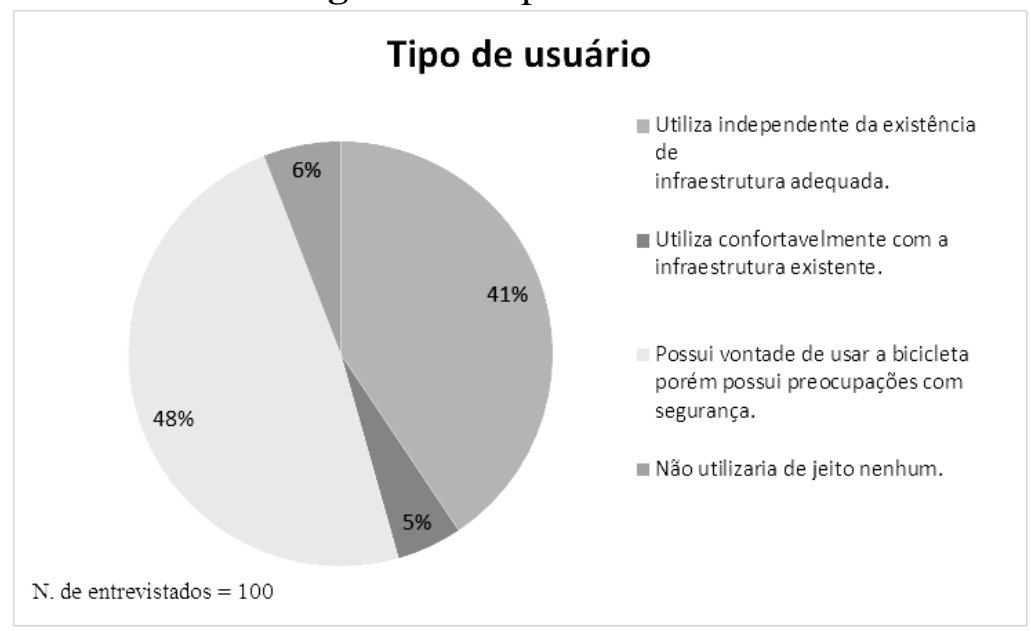

Fonte: Autores.

Ainda de acordo com a pesquisa de percepção da população, quando questionados sobre qual seria o maior desafio enfrentado pelos ciclistas no dia-a-dia, 70\% dos entrevistados responderam que o maior desafio está relacionado à violência no trânsito, devido ao desrespeito dos outros modais de transporte, perante a bicicleta. Complementarmente, quando questionados sobre o potencial da bicicleta em melhorar o trânsito da cidade, $91 \%$ responderam que sim, $8 \%$, talvez, e apenas $1 \%$ respondeu que não acredita que a bicicleta possui esse potencial. A maioria dos usuários de bicicleta da cidade respondeu que utiliza a mesma para lazer $(64,6 \%)$, enquanto a segunda maior finalidade registrada foi ir para a instituição de estudo (37,5\%), conforme a figura 9.

Figura 9 - Finalidade do uso da bicicleta

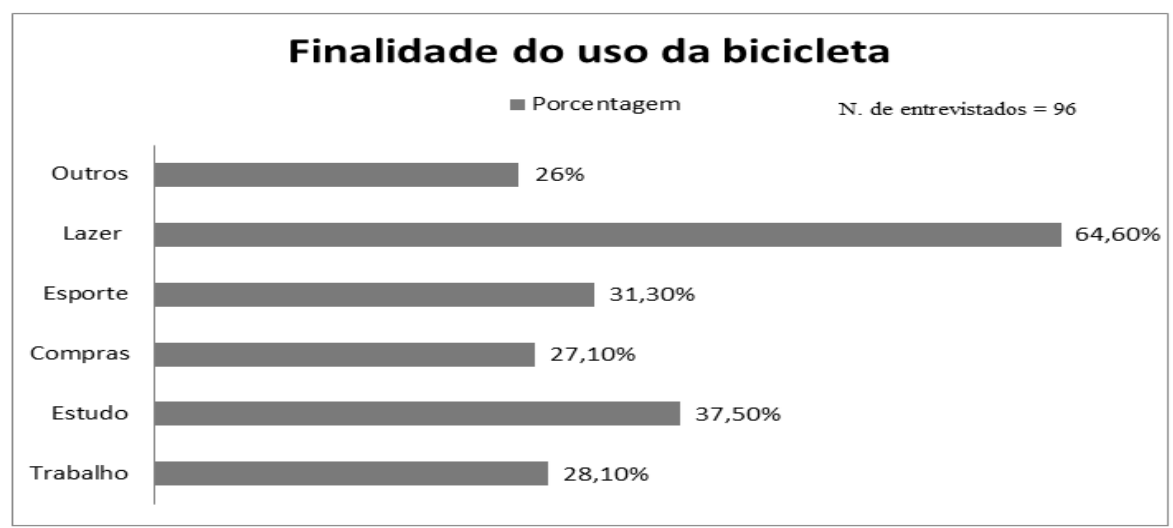

Fonte: Autores. 
Quando perguntado aos especialistas quais as maiores dificuldades para a seleção de políticas públicas, de forma a incentivar um modal de transporte, as principais respostas foram: Descontinuidade no processo de planejamento; Falta de integração entre o planejamento de transportes e o planejamento urbano; Dificuldade para convencer os usuários a abandonarem o modo de transporte motorizado que utilizam atualmente para se locomover. Quando questionados sobre qual o maior desafio que o planejador urbano enfrenta para o estímulo ao uso bicicleta, em relação ao poder público, as principais respostas foram: Falta de mais estudos técnicos capazes priorizarem os sistemas cicloviários; Constante priorização das políticas que estimulam o uso do carro, em vez de estimular o uso da bicicleta; Falta de confiança na bicicleta como um sério modal de transporte.

Quando feita essa mesma pergunta à população, as principais respostas foram: Baixa motivação ao uso diário da bicicleta por parte do cidadão, dando prioridade aos outros modais de transporte; Mostrar a bicicleta como uma solução prática de mobilidade; Facilidade e o conforto, ainda proporcionado pelo uso do carro como modal de transporte; Falta de segurança para o uso da bicicleta. Ainda de acordo com a opinião dos especialistas, pode-se destacar algumas vantagens do uso da bicicleta, como: redução dos impactos ambientais; benefícios à saúde; redução do trânsito nas cidades; benefícios financeiros.

\section{CONCLUSÕES}

A metodologia proposta neste trabalho apresentou uma sequência lógica de etapas capazes de auxiliar o planejador urbano, durante o processo de seleção de políticas públicas de incentivo ao uso da bicicleta para cada área de estudo. $\mathrm{O}$ estudo das políticas adotadas nas regiões mais amigáveis aos ciclistas, no âmbito mundial, serviu de base para a criação de um referencial teórico sobre o que há de mais eficiente, tendo em vista que são locais que de fato tiveram sucesso na aplicação das mesmas.

A pesquisa sobre a percepção da população local, possibilitou entender com clareza seus anseios, em relação ao uso da bicicleta como modal de transporte. Focar nas políticas públicas em consonância com esses anseios, tende a potencializar a eficácia dos investimentos para incentivar o uso da bicicleta. Os dois primeiros filtros propostos permitiram a redução de mais de $40 \%$ do escopo de políticas públicas, que poderiam ser adotadas pelo planejador urbano. Já o terceiro filtro, possibilitou um ordenamento das 
políticas públicas remanescentes, criando uma ordem de prioridades, capaz de auxiliar o planejador a alocar os recursos da área de estudo de maneira mais eficiente. Devido ao seu baixo custo e simplicidade de aplicação, quando comparada aos métodos convencionais de planejamento de transportes, a metodologia proposta permite que mesmo aquelas cidades com maiores restrições orçamentárias, também tenham condições de desenvolver um estudo técnico, consistente durante esse planejamento estratégico.

Recomenda-se para trabalhos futuros nessa linha de pesquisa, a inclusão de mais um filtro, capaz de medir, além da relevância das políticas públicas pela sua incidência, o seu custo de aplicação. Com esse novo filtro seria possível criar uma perspectiva da relação custo-benefício de cada política. Outra recomendação seria a busca por outros quesitos geográficos para aprimorar a correlação entre diferentes regiões como, por exemplo, a configuração do viário do local.

\section{REFERÊNCIAS}

ABRACICLO - Produção de Bicicletas Inicia 2017 com Expectativas Positivas. Noticías. Disponível em: <http://www.abraciclo.com.br/noticias/imprensa/1063-producao-de-bicicletasinicia-2017-com-expectativas-positivas>. Acesso: 02 mar. 2017.

ALVES, Dayane. Niterói é líder em engarrafamento. O FLUMINENSE. 29 mar. 2018. Disponível em: <http://www.ofluminense.com.br/pt-br/cidades/niter\%C3\%B3i-\%C3\%A91\%C3\%ADder-em-engarrafamentos>. Acesso em: 26 jun. 2018.

BBC-BRITISH BROADASTING CORPORATION. Why is cycling so popular in the Netherlands? British Broadcasting Corporation. London, 08 ago. 2013. Disponível em: <http://www.bbc.com/news/magazine-23587916>. Acesso em: 07 abr. 2017.

BBC-BRITISH BROADASTING CORPORATION. Como é viver em Oymyakon, a cidade mais fria do planeta. British Broadcasting Corporation. 29 jan.2018. Disponível em: <https://www.bbc.com/portuguese/internacional-42859597>. Acesso em: 14 jun. 2018.

BERGER, Alex. Danish bike culture even cooler than you thought. The Local, 05 nov. 2014. Disponível em: <https://www.thelocal.dk/20141105/danish-bike-culture-is-even-cooler-thanyou-thought $>$. Acesso em: 11 abr. 2017.

BIRCH, Hayley. Where is the world's hottest city? The Guardian. 22 jul. 2015. Disponível em: $<$ https://www.theguardian.com/cities/2015/jul/22/where-world-hottest-city-kuwait-karachiahvaz>. Acesso em: 14 jun. 2018.

BRASIL. Ministério das Cidades. Programa Bicicleta Brasil: plano de mobilidade por bicicleta nas cidades. Brasilia, DF, 2007.

BRASIL. Sistema de aluguel de bicicletas faz sucesso em todo o País. Portal Brasil, Brasilia, DF, 30 jul. 2014. Disponível em: <http://www.brasil.gov.br/ciencia-e- 
tecnologia/2014/02/sistema-de-aluguel-de-bicicletas-faz-sucesso-em-todo-o-pais>. Acesso em: 02 mar. 2017.

BRASIL. Ministério do Meio Ambiente. Mobilidade Sustável. Brasília, DF. Disponível em: $<$ http://www.mma.gov.br/cidades-sustentaveis/urbanismo-sustentavel/mobilidadesustent\%C3\%A1vel>. Acesso em: 27 out. 2017.

CDOT - CITY OF CHICAGO DEPARTMENT OF TRANSPORTATION. Streets for Cycling Plan 2020. Disponível em:

<https://www.cityofchicago.org/city/en/depts/cdot/provdrs/bike/svcs/bike_planning.html>. Acesso em: 28/04/2017

CHOI, Yoonnjong. Cycling Policies for the Sustainable City: the Case of the City of Seoul. Uppsala, Suécia, 2014.63 f. (Tese Mestrado em Desenvolvimento Sustentável) - Departamento f Earth Sciences, Uppsala University, Uppsala, 2014. Disponível em: <http://www.divaportal.org/smash/get/diva2:689876/FULLTEXT01.pdf >. Acesso em: 27 out. 2017.

CITY OF COPENHAGEN. The City of Copenhagen's Bicycle Strategy 2011-2025, 2011. Disponível em: <http://www.eltis.org/sites/default/files/casestudies/documents/copenhagens_cycling_strategy.pdf>. Acesso: 10 abr. 2018.

CITY OF GRONINGEN. We are Groningen Cycling City - Cycling Strategy 2015 - 2025. City of Groningen. Mai. 2015. Disponível em: <https://groningenfietsstad.nl/en/cycling-strategy/ >. Acesso em: 22 nov. 2017.

CITY OF HELSINK. Helsinki Bicycle Account 2015. Disponível em: $<$ https://issuu.com/helsinkisuunnittelee/docs/pyorailykatsaus_2015_en_issuu >. Acesso em: 10 abr. 2018.

COPENHAGENIZE DESIGN COMPANY. Almetyevsk Bicycle Strategy: Phase one - $50 \mathrm{~km}$ Network, 2016. Disponível em:

<http://copenhagenize.eu/dox/Almetyevsk_Bicycle_Strategy_2016_by_Copenhagenize.pdf >. Acesso em: 28 abr. 2017.

CTB - Código de Trânsito Brasileiro, instituído pela lei nº 9.503, de 23/09/97. Brasília: DENATRAN, 1997.

DANIS ARCHITECTURE CENTER. Copenhagen: the world's best city for cyclist. DAC\&Cities, 21 jan. 2014. Disponível em: <http://www.dac.dk/en/dac-cities/sustainablecities/all-cases/transport/copenhagen-the-worlds-best-city-for-cyclists/>. Acesso em: $11 \mathrm{abr}$. 2017.

EU VOU DE BIKE. China e o aluguel de bicicletas, 2011. Disponível em: <http://www.euvoudebike.com/2011/06/china-e-o-compartilhamento-de-bicicletas/>. Acesso em: 06 abr. 2017.

GENGHINI, Aurélio Barberato. Políticas públicas para o uso da bicicleta como meio de transporte para o trabalho: entre a realidade e a utopia. Metodologia para planejamento de um sistema cicloviário. Revista Direito e Liberdade, v.16 , n.1, p. 135-169, 2014. Disponível em: < http://www.esmarn.tjrn.jus.br/revistas/index.php/revista_direito_e_liberdade/article/view/601 >. Acesso: 10 abr. 2018. 
GOODRIDGE, Steven G. Land-use, Climatic, Demographic and Cultural Issues Affecting Utilitarian Bicycle Travel in the Triangle. Disponível em:

<http://www.humantransport.org/bicycledriving/cyclinguse.htm>. Acesso em: 18 mai 2015.

IBGE - INSTITUTO BRASILEIRO DE GEOGRAFIA E ESTATÍSTICA. Projeção da população do Brasil e das Unidades da Federação, 2017. Disponível em:

<http://www.ibge.gov.br/apps/populacao/projecao/>. Acesso em: 02 mar. 2017.

LARA, A. M. B.; MOLINA, Adão Aparecido. Pesquisa Qualitativa: apontamentos, conceitos e tipologias. In: Cèzar de Alencar Arnaut de Toledo; Maria Teresa Claro Gonzaga. (Org.).

Metodologia e Técnicas de Pesquisa nas Áreas de Ciências Humanas. Maringá: EEduem, 2011, v. 01, p. 121-172.

MATOS, Manuel António Cerqueira da Costa. Conceitos Úteis. Faculdade de Engenharia da Universidade do Porto, 2018. Disponível em: <https://paginas.fe.up.pt/ mam/normetr.pdf〉. Acesso em 22 mai. 2018.

MONTEIRO, Fernanda Borges; CAMPOS, Vânia Barcellos Gouvêa. Analisando viagens a pé e por bicicletas na integração com transporte de massa. Instituto Militar de Engenharia, Rio de janeiro, RJ. p. 6. 2011. Disponível em:

<http://aquarius.ime.eb.br/ webde2/prof/vania/pubs/2011/ANTP_2011.pdf >. Acesso em: 09 jun. 2016.

MOREIRA, Luiz Paulo. Distância entre dois pontos. UOL, 2018. Disponível em:

<https://escolakids.uol.com.br/distancia-entre-dois-pontos.htm>. Acesso em: 21 jun. 2018.

NASCIMENTO, Francisco Paulo do; SOUZA, Flavio Luis L. Metodologia da Pesquisa

Científica - Teoria e Prática. Brasília: THESAURUS, 2015. 384 p.

PAIVA, M. Fatores que influenciam o uso da bicicleta de forma integrada com o metrô. Tese submetida ao Departamento de Engenharia Civil e Ambiental da Faculdade de Tecnologia da Universidade de Brasília, como parte dos requisitos necessários para obtenção do grau de Doutor em Transportes. UnB. Brasília, DF. 2013.

PREFEITURA DA CIDADE DE SÃO PAULO. Ciclovias - Utopia ou Realidade. Transporte Sustentável. Secretaria de Relações Internacionais, 2006. Disponível em:

<http://www.aulasaopaulo.sp.gov.br/transportesustentavel3.htm>. Acesso em: 17 mar. 2017.

PREFEITURA DE NITERÓI. NITtrans - Niterói, Transporte e Trânsito S/A. Geração de Viagens Uso Residencial, 2011.

PRESTO - Promoting Cycling for Everyone as a Daily Transport Mode. PRESTO Cycling Policy Guide: cycling infrastructure, 2010. Disponível em:

$<$ https://ec.europa.eu/energy/intelligent/projects/sites/ieeprojects/files/projects/documents/presto _policy_guide_cycling_infrastructure_en.pdf $>$. Acesso em 10 abr. 2018.

PUCHER, John. Bicycling boom in Germany: a revival engineered by public policy.

Transportation Quaterly, v.51, n.4, p.31-46, 1977.

RELIANCE FOUNDRY. Bike Culture: Europe vs America, 2015. Disponível em:

<http://www.reliance-foundry.com/blog/biking-usa-europe\#gref>. Acesso em: 11 abr. 2017, 
ROSENBERG ASSOCIADOS. O uso da bicicleta no Brasil: qual o melhor modelo de incentivo, 2015. Disponível em: <http://www.abraciclo.com.br/downloads/34-seguranca/968estudo-rosenberg>. Acesso em 14 de mar. 2017.

SODRÉ, Leonardo. Prefeitura de Niterói anuncia pacote que inclui intervenções da Alameda à Região Oceânica. O GLOBO, 31 mar. 2018. Disponível em:

$<$ https://oglobo.globo.com/rio/bairros/prefeitura-de-niteroi-anuncia-pacote-que-incluiintervencoes-da-alameda-regiao-oceanica-22540642>. Acesso em: 28 jun. 2018.

SPINGNARDI, Mariana de Cilo Malufe; MONTEIRO Leonardo Marques. A influência das variáveis microclimáticas na decisão pelo uso da bicicleta em centro urbanos: uma revisão da literatura. Pesquisa em Arquitetura e Construção, Campinas, SP. v. 8, n. 4, p. 220-235, dez 2017.

UN-Habitat - UNITED NATIONS. Promoting Non-Motorized Transport in Asian Cities: Policymakers' Toolbox. New York, NY. dez. 2013. Disponível em:

$<$ https://unhabitat.org/books/promoting-non-motorized-transport-in-asian-cities-policymakerstoolbo//>. Acesso em: 27 out. 2017.

VAN DER ZEE, R. How Amsterdam became the bicycle capital of the world. The Guardian. 05 mai. 2015. Disponível em: <https://www.theguardian.com/cities/2015/may/05/amsterdambicycle-capital-world-transport-cycling-kindermoord>. Acesso em: 07 abr. 2017.

VELASCO, Clara; REIS, Tiago. Em 3 anos, malha cicloviária mais que dobra de tamanho nas capitais do país. G1, 2017. Disponível em: <https://g1.globo.com/economia/noticia/em-3-anosmalha-cicloviaria-mais-que-dobra-de-tamanho-nas-capitais-do-pais.ghtml >. Acesso em: 22 jun. 2018.

WCED - World Commission on Environment and Development (1987). Our common future. Oxford, UK: Oxford UniversityPress. 1987.

World Weather Online. World Weather, 2018. Disponível em: < https://www.worldweatheronline.com/>. Acesso em: 10 abr. 2018.

Recebido em: 2021

Aprovado em: 2021

Publicado em: 2021 